\title{
The Oxidation of Glycine and Propionic Acid in Propionic Acidemia with Ketotic Hyperglycinemia
}

\author{
Toshiyuki Ando, William L. Nyhan ${ }^{[30]}$, James D. Connor, Karsten Rasmussen, George Donnell, \\ Nigholas Barnes, Dennis Cottom, and David Hull \\ Departments of Pediatrics, University of California, San Diego, La Jolla, and University of Southern California, \\ Los Angeles, California (USA); and Hospital for Sick Children, London, England
}

\section{Extract}

Ketotic hyperglycinemia is a syndrome in which elevated concentrations of glycine occur in body fluids of patients who manifest life-threatening episodes of ketoacidosis very early in life. The disorder originally described under this heading is now known to be more reliably categorized by propionic acidemia than by hyperglycinemia. Studies of the metabolism of glycine and of propionate in this condition have been undertaken. Conversion of glycine- $1-{ }^{14} \mathrm{C}$ and of propionate- $1-{ }^{14} \mathrm{C}$ to ${ }^{14} \mathrm{CO}_{2}$ has been studied both in vivo and in vitro. Conversion of glycine-2 $-{ }^{14} \mathrm{C}$ to serine $-3-{ }^{14} \mathrm{C}$ has been studied in vivo. It was found that the conversion of glycine- $1-{ }^{14} \mathrm{C}$ to $\mathrm{CO}_{2}$ in vivo was defective in all three of the patients with ketotic hyperglycinemia. At the earliest time points, the specific activities of expired $\mathrm{CO}_{2}$ in control subjects varied from 25 to more than 60 $\mathrm{dpm} / \mu$ mole, whereas in patients these values did not exceed 10 and were less than 5 in two patients. Conversion of the second carbon of glycine to the third carbon of serine was normal. The relative specific activity of the third carbon was 20 . This value was 2-10 times the values found previously in patients with nonketotic hyperglycinemia where this conversion is defective. Conversion of propionate- $1{ }^{14} \mathrm{C}$ to $\mathrm{CO}_{2}$ was defective both in vivo and in vitro in patients with ketotic hyperglycinemia and with methylmalonic acidemia. In control subjects, specific activities of the $\mathrm{CO}_{2}$ expired following injection of propionate- $1-{ }^{14} \mathrm{C}$ approximated $200 \mathrm{dpm} / \mu$ mole at the earliest time points, whereas in $V B$ the comparable specific activity was close to 0 . Activity of propionylcoenzyme A ( CoA) carboxylase was absent in the fibroblasts of a patient with ketotic hyperglycinemia. Values of $15-30 \mathrm{dpm} / 5 \mathrm{mg}$ protein obtained in the patient do not seem to differ significantly from 0 , whereas in control subjects the values ranged from 985 to $2655 \mathrm{dpm} / 5 \mathrm{mg}$ protein. These observations indicate that there are defects in the metabolism of both glycine and propionate in patients with ketotic hyperglycinemia.

\section{Speculation}

In propionic acidemia with ketotic hyperglycinemia there is a defect in the oxidation of both propionate and glycine in vivo. Propionate carboxylation has been demonstrated to be defective in vitro. The abnormality of propionate metabolism seems to be primary; that of glycine metabolism may be secondary, or both could reflect a defect in synthesis of a common cofactor. 


\section{Introduction}

Ketotic hyperglycinemia is a syndrome in which elevated concentrations of glycine occur in body fluids of patients who manifest life-threatening episodes of ketoacidosis very early in life. A number of inborn errors of metabolism are now known to present with this clinical picture. The extent of heterogeneity has probably only begun to be defined. The disorder originally described as idiopathic hyperglycinemia [7], and later as ketotic hyperglycinemia [17] to distinguish it from nonketotic hyperglycinemia, is characterized by propionic acidemia [3, 9]. In fact, propionic acidemia seems to be a more reliable characteristic of the condition than does hyperglycinemia. A syndrome of propionic acidemia reported by Hommes and colleagues [11] in a patient who died at 5 days of life with metabolic acidosis but without hyperglycinemia probably represents the same disorder. The clinical features of ketotic hyperglycinemia are also found regularly in methylmalonic acidemia [15], and they may be found in isovaleric acidemia [1].

Attacks of ketoacidosis in both ketotic hyperglycinemia with propionic acidemia and methylmalonic acidemia may be induced by the feeding of protein. Dissection of the components of protein that are toxic indicated that both are multiple amino acid toxicities, the former to leucine, isoleucine, valine, threonine, and methionine, and the latter to all of these except leucine. The patterns of amino acid toxicity along with information on the metabolic sources of methylmalonic acid led to the search for propionic acidemia in ketotic hyperglycinemia. They led us at the same time to an exploration of the oxidation of propionic acid in this condition. Studies of glycine metabolism were undertaken after our investigation of glycine metabolism in nonketotic hyperglycinemia [2]. These studies have indicated that there are defects in the oxidation of both propionate and glycine in patients with propionic acidemia and ketotic hyperglycinemia.

\section{Materials and Methods}

Three patients with clinical ketotic hyperglycinemia were studied who have been documented as having propionic acidemia [3, 27]. KH had been diagnosed early in life and treated with careful dietary control. She had no neurologic or mental impairment. She had been in remission for a prolonged period; she was 5 years old and weighed $11.6 \mathrm{~kg}$ at the time of study. The concentrations of glycine and propionate in her plasma were 410 and $10.4 \mu$ moles/liter. The glycine concentration had previously been 3 times as high. CE was a classical case with advanced physical and mental retardation. He was 4.5 years old and weighed $14.3 \mathrm{~kg}$ when the experiment was performed. The concentrations of glycine and propionate in his plasma were 1150 and $23.9 \mu$ moles/liter. $V B$ had been diagnosed early and treated vigorously, but he had fed poorly, vomited frequently, and had not thrived. He was 13 months old and weighed $6.7 \mathrm{~kg}$ at the time of study. The concentrations of glycine and propionate in his plasma were 249 and $23.7 \mu$ moles/liter. The glycine concentration had previously been as high as 8 times that level. Normal mean concentrations of glycine and propionate in this laboratory are 146 and $1.6 \mu$ moles/liter.

Studies of Glycine and Propionate Metabolism in Vivo

Glycine- $1-{ }^{14} \mathrm{C}$, glycine-2-214 $\mathrm{C}$, and sodium propionate${ }^{1-14} \mathrm{C}$ had specific activities of $16.0,19.4$, and 9.78 $\mathrm{mCi} / \mathrm{mmole}$, respectively [22]. The procelures and analytical methods have been described previously [2]. In each instance, the isotope was injected intravenously in a dose of $2 \mu \mathrm{Ci} / \mathrm{kg}$. Expired air was collected at intervals, its $\mathrm{CO}_{2}$ was trapped in ethanolamine, and its isotope and $\mathrm{CO}_{2}$ content were determined. Control data on glycine metabolism have been published $[2,5]$. Control subjects for the study of propionate metabolism were a patient, $L G$, with $\mathrm{B}_{12}$-independent methylmalonic acidemia [15]; a patient, $D G$, with cerebral gigantism [6]; and a patient, $A M c$, with the Cornelia de Lange syndrome. This permitted comparison of a patient with a known defect in propionate metabolism and two patients with no demonstrable metabolic defect [27]. Their ages and weights at the time of study were $L G: 2$ years, $9.7 \mathrm{~kg} ; D G: 2$ years, $15.7 \mathrm{~kg} ; A M c: 6$ years, $10.7 \mathrm{~kg}$.

\section{Studies of the Oxidation of Propionate in Vitro}

Fibroblasts were cultured following skin biopsy of patients $K H$ and $C E$ and of a number of control individuals. Cells in culture were also available from $L G$, the patient with methylmalonic acidemia, and from $S F$, a patient with nonketotic hyperglycinemia. The cells were grown in minimal essential medium or in diploid growth medium [23] which contained $10 \%$ fetal calf serum, penicillin, and streptomycin in $250-\mathrm{ml}$ disposable flasks [24].

Two types of assay were performed which have been termed large and medium scale, respectively. For the large scale assay, cells from three to six $250-\mathrm{ml}$ flasks were transferred to a 4-liter Fernbach flask and were 


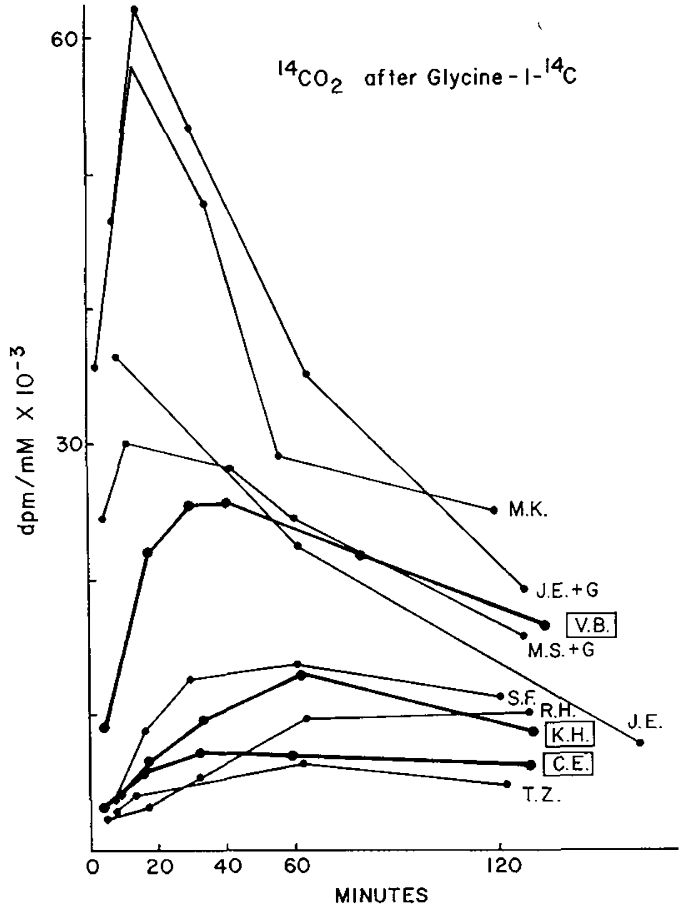

Fig. 1. Conversion of glycine- $-{ }^{14} \mathrm{C}$ to respiratory ${ }^{14} \mathrm{CO}_{2}$ in vivo. Initials of the patients $V B, K H$, and $C E$ are outlined, and the lines representing the spccific activities of their ${ }^{14} \mathrm{CO}_{2}$ are heavier than the others. $M K, J E$, and $M S$ were control subjects. $S F, R H$, and $T Z$ were patients with nonketotic hyperglycinemia [2, 5]. The designation $+G$ indicates the creation of a large glycine pool in a control subject by continuous infusion of nonisotopic glycine.

grown until there was a confluent mass of cells on the bottom. The medium was removed and the cells were rinsed twice with bicarbonate buffer, $\mathrm{pH} 7.6$ [8]. Buffer $(25 \mathrm{ml})$ was added to the flask. The flask was air-sealed, using a rubber stopper with two glass tubes which served as inlet and outlet, and saturated with $5 \% \mathrm{CO}_{2}$. The glass tubes were sealed by closing the pinchcocks on the attached rubber tubes. Incubation was initiated by the addition of $1 \mu \mathrm{Ci}$ sodium propionate- $1-^{14} \mathrm{C}$ and was conducted on a mechanical shaker at $37^{\circ}$ for 30 $\min$. The reaction was terminated by the addition of 6 $\mathrm{ml} 1 \mathrm{~N} \mathrm{HClO}_{4}$. A rubber breathing bag containing 13 liters of nitrogen was connected to the inlet tubing, the outlet tubing was connected to the $\mathrm{CO}_{2}$-trapping apparatus [2], and the motor was turned on. The gas in the flask was replaced with nitrogen, and the $\mathrm{CO}_{2}$ was trapped in ethanolamine and methyl Cellosolve. The isotope content of the $\mathrm{CO}_{2}$ was determined after it was mixed with toluene-methyl Cellosolve containing 2,5-diphenyloxazole [13]. A blank incubation was carried out without cells. Mass of the cells studied was determined after the cells were scraped off the bottom of the flask with a rubber policeman. The contents of the flask were transferred to a preweighed $40-\mathrm{ml}$ centrifuge tube; the sediment was washed successively with ethanol, $50 \%$ ethanol in ether, and ether, and was then dried overnight in a desiccator. The weight of the dried cell residue was determined.

For the medium scale assay, the cells of a $250-\mathrm{ml}$ flask were used and the reaction was carried out in the flask. The procedure was the same as that in the large scale assay except that $5 \mathrm{ml}$ bicarbonate buffer and 2.5 $\mu \mathrm{Ci}$ sodium propionate- $1{ }^{-14} \mathrm{C}$ (specific activity, 5.4 $\mathrm{mCi} / \mathrm{mmole}$ ) were used. The protein content of the cells was determined by the biuret reaction [10].

$\mathrm{CO}_{2}$ Fixation in Vitro

Propionyl-CoA was synthesized by the method of Simon and Shemin [19], and coenzyme A [25] and propionic anhydride [26] were purchased. The yield of propionyl-CoA was determined by the hydroxylamine reaction. The assay for propionyl-CoA carboxylase was a modified form of that of Tietz and Ochoa [21]. Four flasks of fibroblasts were harvested after trypsinization in $0.05 \mathrm{M}$ Tris-HCl buffer, $\mathrm{pH} 7.5$, containing $1 \mathrm{~mm}$ ethylenediaminetetraacetic acid and $0.5 \mathrm{~mm}$ reduced glutathione. The cells were sedimented by centrifugation at $1800 \mathrm{rpm}$ at $4^{\circ}$. After resuspension in a small amount of buffer, the cells were frozen and thawed and then centrifuged at $8000 \times g$. Supernatant solution in aliquots of $0.5 \mathrm{ml}$ was used in the assay. The reaction was initiated by adding $0.34 \mu$ moles propionyl-CoA and $0.426 \mu$ moles $(2 \mu \mathrm{Ci}) \mathrm{NaH}^{14} \mathrm{CO}_{3}$ in a Warburg flask. The incubation was carried out in a total volume of $1.5 \mathrm{mI}$ at $37^{\circ}$ for $20 \mathrm{~min}$ in air. The reaction was terminated by the addition of $0.2 \mathrm{ml} 30 \%$ trichloroacetic acid, and the reaction mixture was transferred to a conical centrifuge tube. An aliquot of clear supernatant solution was pipetted into a scintillation-counting vial; $\mathrm{CO}_{2}$ was removed from the vial by heating under an infrared lamp overnight. The contents of the vial were redissolved in $1 \mathrm{ml} \mathrm{H}_{2} \mathrm{O}$ and mixed with Bray's scintillation mixture; radioactivity was determined in a liquid scintillation counter. Two blank incubations were prepared, a blank without cells and a blank with boiled control cells. Protein content was determined by the biuret reaction. All assays were done in duplicate.

\section{Results}

\section{The Oxidation of Glycine in Vivo}

Data on the conversion of intravenously injected glycine- ${ }^{-14} \mathrm{C}$ to respiratory $\mathrm{CO}_{2}$ are illustrated in Fig- 
ure 1. The concentrations of glycine and propionate in the plasma at the start of the experiment have been given under Methods. For the control subjects, the initial concentrations of glycine, in micromoles per liter, were as follows: $J E, 150 ; M K, 214 ; J E+\mathrm{G}, 756$; and $M S+G$, 586. In the $+G$ control experiments, glycine was infused at a rate of $60 \mathrm{mg} / \mathrm{kg}$ for $60 \mathrm{~min}$ prior to the injection of the isotope and for $60 \mathrm{~min}$ thereafter. In control subjects, glycine is rapidly decarboxylated in vivo. Curves representing patients $\mathrm{KH}$ and $C E$ were rather flat, rising slowly to maximum specific activities at $30-60 \mathrm{~min}$ and then gradually declining; in contrast, curves for control subjects declined rapidly from peak levels at 10-20 min. The curves for $K H$ and $C E$ were indistinguishable from those for $R H, T Z$, and $S F$, the latter being patients with nonketotic hyperglycinemia who have a defect in the conversion of the first carbon of glycine to $\mathrm{CO}_{2}[2$, 5]. In $V B$, the defect was much less prominent except at the earliest time point, after which specific activity rose so that by $60 \mathrm{~min}$ the values for this patient could not be distinguished from those for control subjects. Nevertheless, at the earliest time points the data for all

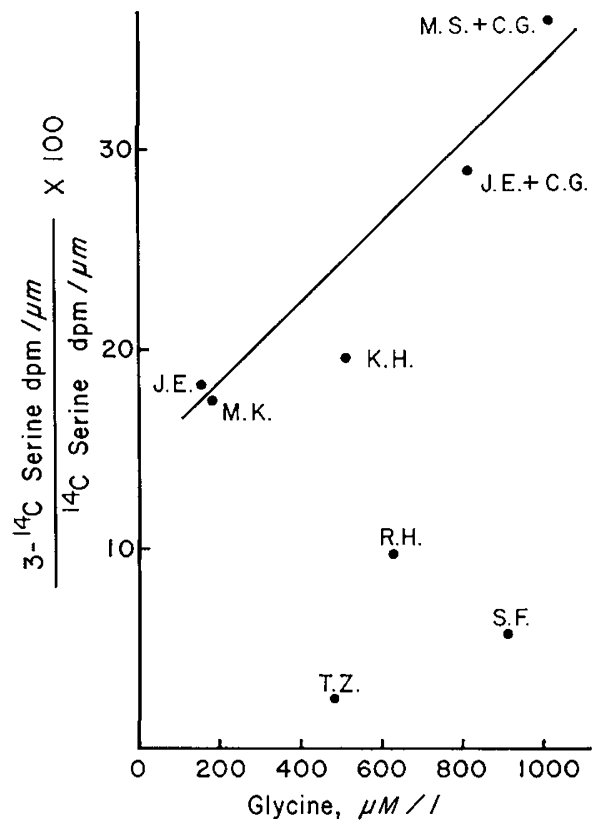

Fig. 2. Conversion of glycine-2-2 ${ }^{x 4} \mathrm{C}$ to carbon 3 of serine. The data represent the ratios of the specific radioactivity of the formaldemethone derivative of carbon 3 of serine to the specific activity of the serine of plasma. The line was fitted manually. Data on control subjects $J E, M K$, and $M S$ and on patients with nonketotic hyperglycinemia $T Z, R H$, and $S F$ have previously been reported $[2,5]$. $K H$ was a patient with ketotic hyperglycinemia. The designation + C.G. indicates the creation of a large glycine pool by continuous infusion of nonisotopic glycine.

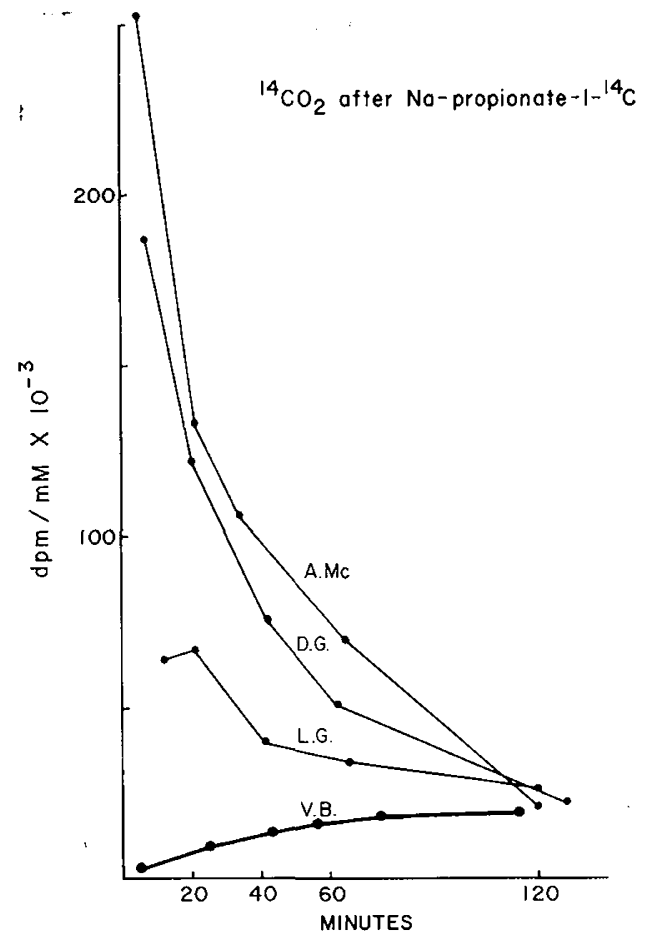

Fig. 3. The conversion of sodium propionate-1-14 $\mathrm{C}_{1}$ to ${ }^{14} \mathrm{CO}_{2}$ in vivo. The data represent the specific activities of respiratory $\mathrm{CO}_{2}$ collected after intravenous injection of the tracer. $V B$ was a pa. tient with ketotic hyperglycinemia, $L G$ was a patient with methylmalonic acidemia, and $A M C$ and $D G$ were control subjects.

three patients were clearly distinguishable from those for control subjects. Initial specific activities differed by factors of $2-15$.

The different curve obtained for $V B$ could reflect molecular and metabolic heterogeneity in this condition, and he did appear different clinically. It is also true that, at the time of the study, he had a considerably lower concentration of glycine in his plasma than did the other patients. Data obtained for controls subjects in the $+G$ experiments indicate that, although there is dilution of injected glycine in an abnormally large pool, the larger pool actually stimulates oxidation so that higher rather than lower specific activities were obtained in the presence of the larger pools. The same might not apply, of course, in the presence of a defect in oxidation, and the differences between $V B$ and the other two patients could reflect differences in dilution.

Conversion of Glycine-2-14C to Serine and to Carbon 3 of Serine in Vivo.

Conversion of glycine-2- ${ }^{14} \mathrm{C}$ to serine was studied in $K H$ by the isolation of glycine and serine from the blood at intervals during $1 \mathrm{hr}$ following the injection 
Table I. Formation of ${ }^{14} \mathrm{CO}_{2}$ from propionate- $1-{ }^{14} \mathrm{C}$ in fibroblasts ${ }^{1}$

\begin{tabular}{lc}
\hline Subject ${ }^{2}$ & $\begin{array}{c}{ }^{4} \mathrm{CO}_{2}, \mathrm{dpm} / 10 \mathrm{mg} \\
\text { dried cells }\end{array}$ \\
\hline$K H$ & 552 \\
$L G$ & 943 \\
$D B$ & 9296 \\
$J P$ & 5562 \\
$D G$ & 4735 \\
\hline
\end{tabular}

1 The system contained $25 \mathrm{ml}$ bicarbonate buffer ( $\mathrm{pH} 7.6)$ and $1 \mu \mathrm{Ci}$ sodium propionate- $1{ }^{14} \mathrm{C}(9.78 \mathrm{mCi} / \mathrm{mmole})$. A blank incubation was carried out without cells. Weights of the dried residues ranged from 6.7 to $14.3 \mathrm{mg}$.

${ }^{2} K H$ was a patient with ketotic hyperglycinemia, $L G$ was the patient with methylmalonic acidemia, and $D B, J P$, and $D R$ were control subjects.

Table II. Formation of ${ }^{14} \mathrm{CO}_{2}$ from propionate- $1-{ }^{14} \mathrm{C}$ in fibroblasts ${ }^{1}$

\begin{tabular}{cccc}
\hline Subject ${ }^{2}$ & ${ }^{14} \mathrm{CO}_{2}, \mathrm{dpm} /$ flask & Protein, mg/flask & $\begin{array}{c}{ }^{14} \mathrm{CO}_{2}, \mathrm{dpm} / \mathrm{mg} \\
\text { protein }\end{array}$ \\
\hline$C E$ & 8,413 & 0.49 & 16,710 \\
$S F$ & 70,680 & 0.37 & 189,060 \\
$B R$ & 58,980 & 0.34 & 171,330 \\
$E D$ & 58,350 & 0.40 & 144,060 \\
$S P$ & 80,620 & 0.62 & 128,960 \\
\hline
\end{tabular}

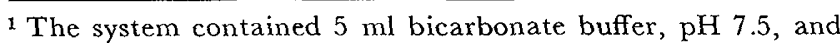
$2.5 \mu \mathrm{Ci}$ sodium propionate- $1{ }^{14} \mathrm{C}(5.4 \mathrm{mCi} / \mathrm{mmole})$. Blank incubations were carried out with no cells and with boiled cells, and final values were corrected by the average of these blanks.

${ }^{2} C E$ was the patient with ketotic hyperglycinemia, and $S F$ the patient with nonketotic hyperglycinemia; the others were normal individuals.

of the isotope. Specific activities of the serine in plasma of $K H$ were within the normal range [2]. Serine was isolated from the plasma and degraded with periodate. The released carbon 3 was reacted with dimedon, and the formalde-methone derivative was isolated [2]. The relative specific activities of the carbon 3 of serine in $K H$ were within the normal range. Figure 2 illustrates the specific activities of carbon 3 of serine at $8 \mathrm{~min}$ in $\mathrm{KH}$ and in a series of control subjects $(J G$, $M K$, and $M S)$. The relation between the concentration of glycine in plasma and the rate of conversion of carbon 2 of glycine to carbon 3 of serine is illustrated by the line drawn for the control values. In individuals without abnormality in glycine metabolism, conversion of carbon 2 of glycine to carbon 3 of serine is increased proportionally to the concentration of plasma glycine. These data and the data on $\mathrm{CO}_{2}$ suggest an induction of the activity of the enzyme which converts glycine to $\mathrm{CO}_{2}, \mathrm{NH}_{3}$, and hydroxymethyltetrahydrofolate. Another possibility is an enzyme with a high $K_{m}$. Data for $K H$ were qualitatively different from those for the patients with nonketotic hyperglycinemia in which this activity is. considered to be defective. In $\mathrm{KH}$ the relation between conversion and glycine concentration suggests that the control mechanism responsive to increases in glycine concentration is intact. We concluded that the conversion of glycine-2${ }^{14} \mathrm{C}$ to serine- $3-{ }^{14} \mathrm{C}$ was normal in $K H$.

\section{The Oxidation of Propionate in Vivo}

The isotope content of respiratory $\mathrm{CO}_{2}$ after the intravenous injection of sodium propionate- $1^{-14} \mathrm{C}$ is illustrated in Figure 3. This experiment was performed on patient $V B$; on control subjects $D G$ and $A M C$; and on $L G$, a patient with methylmalonic acidemia who provided a control with a known defect in propionate metabolism. In control individuals, conversion of propionate to $\mathrm{CO}_{2}$ was very rapid, and specific activities approximated $200,000 \mathrm{dpm} / \mathrm{mmole}$ at the earliest time points. The curves then descended rapidly during the first $60 \mathrm{~min}$. In contrast, for $V B$, the patient with ketotic hyperglycinemia, the curve was relatively flat, rising slowly throughout the $2 \mathrm{hr}$ of study as if some product of propionate was slowly being synthesized that then served as a source of $\mathrm{CO}_{2}$. The curve for the patient with methylmalonic acidemia was intermediate, certainly lower than normal, but much higher than that of $V B$ and, by contrast, of relatively normal configuration. These data indicate that in ketotic hyperglycinemia there is a striking defect in the oxidation of propionic acid in vivo.

\section{The Oxidation of Propionate in Vitro}

The overall metabolism of propionate was assessed in intact fibroblasts of patients $K H$ and $C E$ by use of sodium propionate-1 $-{ }^{14} \mathrm{C}$. Data on these patients and a series of control subjects are presented in Tables $I$ and II for the large scale and medium scale assays, respectively. In both assays, cells of patients with ketotic hyperglycinemia metabolized the carboxyl group of propionate to $\mathrm{CO}_{2}$ at a rate which was approximately $1 / 10$ those observed in cells of normal individuals.

Decarboxylation of propionate by fibroblasts from $K H$ was even less efficient than in cells of $L G$, the patient with methylmalonic acidemia in whom there was a known defect in propionate metabolism (Table I). Comparison with control subjects indicated clearly a defect in $\mathrm{KH}$ in the oxidation of propionate. Similar 
observations were made on patient $C E$. The experiment was essentially the same: incubation of labeled propionate with attached cells in bicarbonate buffer. The values obtained (Table II) were somewhat different as the numbers of cells and volume of buffer were smaller and the amount of isotope used was larger. Furthermore, data are expressed per milligram protein rather than per dried cellular weight. The differences between patient and control subject were of the same order of magnitude. Cells from $S F$, a patient with nonketotic hyperglycinemia, carried out the conversion of propionate to $\mathrm{CO}_{2}$ at a perfectly normal rate.

\section{Propionyl-CoA Carboxylase Activity}

The activity of propionyl-CoA carboxylase has been assessed in extracts of fibroblasts of patient CE. The

Table III. Propionyl-CoA carboxylase activity in fibroblasts ${ }^{1}$

\begin{tabular}{|c|c|c|c|c|c|c|}
\hline \multirow[b]{2}{*}{ Subject ${ }^{2}$} & \multicolumn{3}{|c|}{ Experiment 1} & \multicolumn{3}{|c|}{ Experiment 2} \\
\hline & $\begin{array}{l}\mathrm{CO}_{2} \text { fixed, } \\
\mathrm{dpm} / \text { flask }\end{array}$ & $\begin{array}{l}\text { Protein, } \\
\text { mg/lask }\end{array}$ & $\begin{array}{c}\text { Specific } \\
\text { activity, } \\
\mathrm{dpm} / 5 \mathrm{mg}\end{array}$ & $\begin{array}{l}\mathrm{CO} 2 \text { fixed, } \\
\mathrm{dpm} / \text { flask }\end{array}$ & $\begin{array}{l}\text { Protein, } \\
\text { mg/flask }\end{array}$ & $\begin{array}{l}\text { Specific } \\
\text { activity, } \\
\mathrm{dpm} / 5 \mathrm{mg}\end{array}$ \\
\hline$C E$ & 11 & 3.48 & 15 & 22 & 3.48 & 30 \\
\hline$R O$ & 1490 & 4.55 & 1635 & 1767 & 4.55 & 1840 \\
\hline$J G$ & 1639 & 3.34 & 2455 & 1773 & 3.34 & 2655 \\
\hline$E D$ & 1141 & 5.08 & 1125 & 999 & 5.08 & 985 \\
\hline$N A^{3}$ & 1 & 3.08 & & 0 & 3.08 & 0 \\
\hline
\end{tabular}

1 The system contained: Tris-HCl buffer, $\mathrm{pH} 8.2,115 \mu$ moles in $0.5 \mathrm{ml} ; \mathrm{MgCl}_{2}$ and adenosine triphosphate, $3 \mu$ moles of each in $0.1 \mathrm{ml}$; reduced glutathione, $2 \mu$ moles in $0.1 \mathrm{ml}$; fibroblast extract, $0.5 \mathrm{ml}$; propionyl-CoA, $0.34 \mu$ moles in $0.2 \mathrm{ml}$; and $\mathrm{NaH}^{14} \mathrm{CO}_{3}, 2 \mu \mathrm{Ci}(0.426 \mu$ moles $)$ in $0.1 \mathrm{ml}$.

${ }^{2} C E$ was the patient with ketotic hyperglycinemia. The others were control subjects. A blank was run without propionyl-CoA in order to correct for enzymatically catalyzed $\mathrm{CO}_{2}$ fixation reactions independent of propionate metabolism; the amounts of $\mathrm{CO}_{2}$ fixed by extracts of control cells under these conditions approximated those found for $L E$.

${ }^{3}$ Boiled cells. data obtained are compared with those of control individuals in Table III. Cells of $C E$ were completely unable to fix $\mathrm{CO}_{2}$ to propionyl-CoA, whereas this activity was readily demonstrated in extracts of fibroblasts of control individuals. The defect in the enzyme in $C E$ seemed to be complete, which suggests that the limited oxidation of propionate observed in the intact cell system represented the activity of alternative pathways for propionate.

\section{Discussion}

These studies indicate that in ketotic hyperglycinemia there is a defect in the enzyme propionyl-CoA carboxylase. In the patient whom we studied there was no activity in extracts of fibroblasts grown in cell culture. Similarly, no activity of this enzyme has been reported by Hsia and colleagues [12] in extracts of fibroblasts from a patient with this disorder, and very low activity was reported by Gompertz et al. [9] in a mitochondrial preparation from the liver of a patient. These observations provide a site for the molecular understanding of the disease. The precise site could be in the primary structure of the propionyl-CoA carboxylase apoenzyme or in some aspect of cofactor interrelation. It is also possible that these sites will be found to differ in different patients.

Defective oxidation of propionate has been demonstrated in each of the three patients whom we have studied. This defect is demonstrable both in vivo and in vitro. Data obtained in vivo are consistent with the presence of a virtually complete block in the major pathway for propionate. This is in keeping with our understanding of the role of propionyl-CoA carboxylase in the metabolism of propionate via the citric acid cycle (Fig. 4). The demonstration of some oxidation of propionate both in vivo and in vitro as well as the

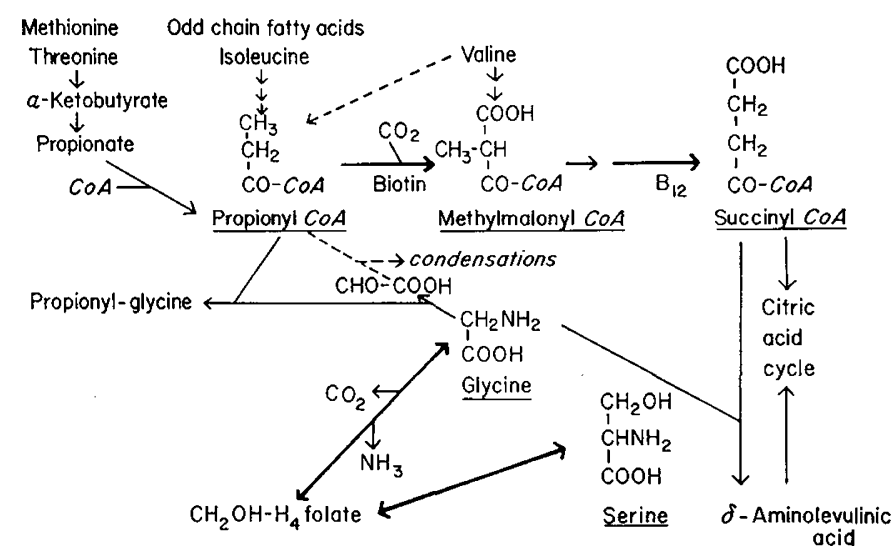

Fig. 4. Metabolic pathways for propionate and glycine. 
shape of the curve obtained in vivo suggest the operation of alternative pathways. The major defect in propionate oxidation is consistent with a primary defect in propionyl-CoA carboxylase. In experiments in progress, the effects of biotin on the metabolism of propionate are under study in cells of patients with propionic acidemia. In control fibroblasts, biotin accelerates the oxidation of propionate to $\mathrm{CO}_{2}$. This effect of biotin was absent in cells of the patient.

Studies of glycine metabolism have indicated that there is also a defect in the oxidation of glycine. This was present in each of the three patients studied. In two, the degree of abnormality as compared with control subjects was as great as the defect in propionate oxidation. It has not been possible to pursue this further as in the case of propionate because glycine oxidation does not take place in fibroblasts. Glycine is nevertheless very actively decarboxylated in vivo [2]. A glycine decarboxylase system has been described in mammalian liver [16] which is similar to those previously described in Peptococcus glycinophilus [14] and in avian liver [18]. This system converts glycine to $\mathrm{CO}_{2}, \mathrm{NH}_{3}$, and a single carbon tetrahydrofolate derivative, which then can react with other compounds to provide a methyl or hydroxymethyl group, for instance, with another molecule of glycine to form serine. Our data on nonketotic hyperglycinemia $[2,5]$ are consistent with a defect in this system. This conclusion is supported by the study of glycine metabolism in vitro in liver of a patient with nonketotic hyperglycinemia [20]. In ketotic hyperglycinemia, on the other hand, the defect in conversion of the first carbon of glycine to $\mathrm{CO}_{2}$ may be as severe as in nonketotic hyperglycinemia, but there is no defect in the formation of the one carbon precursor of carbon 3 of serine from the second carbon of glycine.

It is possible that the defect in glycine metabolism is in some way secondary to a primary defect in propionate metabolism. This hypothesis is favored by the fact that hyperglycinemia also occurs in methylmalonic acidemia and in isovaleric acidemia. However, glycine oxidation in vivo is normal in isovaleric acidemia [1]. The oxidation of glycine-1 ${ }^{14} \mathrm{C}$ has not been studied in vivo in methylmalonic acidemia. It is also possible that defects in both glycine and propionate oxidation in ketotic hyperglycinemia are secondary to a defect in the synthesis of a common cofactor. The observation that propionic acidemia in one of these patients was sensitive to biotin [4] is of considerable interest in this regard, as well as providing the possibility of therapeutic management in those patients who respond.
Defective oxidation of propionate has also been demonstrated in these studies both in vivo and in vitro in a patient with methylmalonic acidemia. In this instance the defect, which is clearly secondary (but to a block in a subsequent step of propionate metabolism), led to an abnormality in propionate oxidation in vivo which was less marked than that observed in ketotic hyperglycinemia. The different patterns obtained in the two curves suggest that the defect in methylmalonyl-CoA mutase in our patient with methylmalonic acidemia is a partial one, whereas the defect in propionyl-CoA carboxylase in our patient with ketotic hyperglycinemia is complete and the propionate oxidized is metabolized slowly through a pathway other than the major one. It does remain possible, however, that the low rate of propionate oxidation in vivo could be accounted for by a residual amount of propionyl-CoA carboxylase activity, despite the virtual absence of this activity in extracts of cultured fibroblasts.

\section{Summary}

The metabolism of glycine and of propionate have been studied in three patients with propionic acidemia and ketotic hyperglycinemia, in one patient with methylmalonic acidemia, and in a number of control individuals. Defective oxidation of propionate to $\mathrm{CO}_{2}$ has been documented both in vivo and in vitro. Absence of activity of propionyl-CoA carboxylase has been demonstrated in the fibroblasts of a patient with ketotic hyperglycinemia. A defect in the oxidation of glycine- ${ }^{14} \mathrm{C}$ to $\mathrm{CO}_{2}$ has been demonstrated in each patient with ketotic hyperglycinemia.

\section{Reference and Notes}

1. Ando, T., Klingberg, W. G., Ward, A. N., Rasmussen, K., AND NYHAN, W. L.: Isovaleric acidemia presenting with altered metabolism of glycine. Pediat. Res., 5: 748 (1971).

2. Ando, T., Nyhan, W. L., Gerritsen, T., Gong, L., Heiner, D. C., AND Bray, P. F.: Metabolism of glycine in the nonketotic form of hypexglycinemia. Pediat. Res., 2: 254 (1968).

3. Ando, T., Rasmussen, K., Nyhan, W. L., Donnell, G., and Barnes, N. D.: Propionic acidemia in patients with ketotic hyperglycinemia. J. Pediat., 78: 827 (1971).

4. Barnes, N. D., Huli, D., Balgobin, L., and Gompertz, D.: Biotin responsive propionicacidaemia. Lancet, $i: 244$ (1970).

5. Baumgartner, R., Ando, T., and Nyhan, W. L.: Nonketotic hyperglycinemia. J. Pediat., 75: 1022 (1969).

6. Bejar, R. L., Smith, G. F., Park, S., Spellacy, W. N., WolfSON, S. L., AND NYHAN, W. L.: Cerebral gigantism: concentrations of amino acicls in plasma and muscle. J. Pediat., 76: 105 (1970).

7. Childs, B., NyHan, W. L., Bordfn, M. A., BARD, L., AND 
Cooke, R. E.: Idiopathic hyperglycinemia and hyperglycinuria, a new disorder of amino acid metabolism. Pediatrics, 27: 522 (1961).

8. Ellrotr, K. A. G.: Tissue slide technique. In: S. P. Colowick and N. O. Kaplan: Methods of Enzymology, Vol. 1, p. 7. (Academic Press, New York, 1955).

9. Gompertz, D., Storrs, C. N., Bau, D. C. K., Peters, T. J., AND Hughes, E. A.: Localisation of enzymic defect in propionic acidaemia. Lancet, $i$ : 1140 (1970).

10. Henry, R. J., Sobel, C., and Berkman, S.: Interferences with biuret methods for serum proteins. Anal. Chem., 29: 1491 (1957).

11. Hommes, F. A., Kuipers, J. R. G., Elema, J. D., Jansen, J. F., AnD JonXis, J. H. P.: Propionicacidemia, a newborn error of metabolism. Pediat. Res., 2: 519 (1968).

12. Hsia, Y. E., Scully, K. J., and Rosenberg, L. E.: Defective propionate carboxylation in ketotic hyperglycinaemia. Lancet, i: 757 (1969).

13. JeFfaY, H., and Alvarez, J.: Liquid scintillation counting of carbon 14: use of ethanolamine ethylene glycol monomethyl ether toluene. Anal. Chem., 33: 612 (1961).

14. Klein, J. M., and Sagers, R. D.: Glycine metabolism. I. Properties of the system catalyzing the exchange of bicarbonate with the carboxyl group of glycine in Peptococcus glycinophilus. J. Biol. Chem., 241: 197 (1966).

15. Morrow, G., III, Barness, L. A., Auerbach, V. H., DrGeorge, A. M., Ando, T., And Nyhan, W. L.: Observations on the coexistence of methylmalonic acidemia and glycinemia. J. Pediat., 7t: 680 (1969).

16. Motokawa, Y., Hiraga, K., Kochi, H., and Kikuchi, G.: Evidence for the presence of a protein-bound intermediate in the cleavage and the synthesis of glycine. Biochem. Biophys. Res. Commun., 38: 771 (1970).

17. Nyhan, W. L., Ando, T., And Gerritsen, T.: Hyperglycinemia.
In: W. L. Nyhan: Amino Acid Metabolism and Genetic Variation, p. 225. (McGraw-Hill, New York, 1967).

18. Richert, D. A., Amberg, R., And Wilson, M.: Metabolism of glycine by avian liver. J. Biol. Chem., 237: 99 (1962).

19. SrMon, E. J., ANd SHemrn, D.: The preparation of S-succinyl coenzyme A. J. Amer. Chem. Soc., 75: 2520 (1953).

20. Tada, K., Narisawa, K., Yoshida, T., Konno, T., Yokoyama, Y., Nakagawa, H., Tanno, K., Mochizukr, K., Arakawa, Ts., Yoshida, T., AND Kikuchi, G.: Hyperglycinemia: a defect in glycine cleavage reaction. Tohoku J. Exp. Med., 98: 289 (1969).

21. Tietz, A., And OghoA, S.: Metabolism of propionic acid in animal tissues. J. Biol. Chem., 234: 1394 (1959).

22. New England Nuclear Corporation, Boston, Mass.

23. Grand Island Biological Company, Grand Island, N. Y.

24. Falcon Plastics, Los Angeles, Calif.

25. Calbiochem, Los Angeles, Calif.

26. Matheson, Coleman, and Bell, Norwood, O.

27. These experiments were undertaken in accordance with institutional regulations on human experimentation. Written evidence of informed consent was obtained.

28. We wish to thank Mrs. Janette Holm for her able technical assistance.

29. Supported by Public Health Service Research Grants no. HD 04608 from the National Institute of Child Health and $\mathrm{Hu}$ man Development and no. GM 17702 from the National Institute of General Medical Sciences, National Institutes of Health, and by a research grant from the National Founda. tion.

30. Requests for reprints should be addressed to: WILLIAM $\mathbf{L}$. Nyhan, M.D., Ph.D., Department of Pediatrics, University of California, San Diego, P. O. Box 109, La Jolla, Calif. 92037 (USA).

31. Accepted for publication December 7, 1971. 